\title{
Assesment for Learning dalam Pembelajaran Bahasa di Sekolah
}

\author{
Joko Nurkamto ${ }^{1} \&$ Teguh Sarosa ${ }^{2}$ \\ jokonurkamto@gmail.com
}

\begin{abstract}
Previous studies show that assessment for learning (AfL) is reported to give a significant impact on student academic and language skills-related performance, especially when meaningful feedback strategies are adopted. Despite this empirical evidence, in most Asian countries, AfL remains under-practiced particularly in prescribed-mandated curriculum practices where teachers are considered as curriculum transmitters, and exercise-and-test based instruction are still pedagogical rituals in the classrooms. To respond to this critical issue, in this article, we would like to explore assessment for learning (AfL) in teaching. It focuses primarily upon the concept of AfL, the aim of Afl, prerequisite for implementing AfL, and the enactment of AfL for classroom practice. Since AfL practices are of great concern to curriculum policy makers, school leaders, and teacher educators, we conclude our article by offering some practical recommendations.
\end{abstract}

Keywords: academic achievement, assessment for learning, feedback strategies, and student learning

Abstrak: Studi sebelumnya menunjukkan bahwa assessment for learning (AfL) dapat memberikan dampak signifikan pada prestasi akademik dan keterampilan siswa, terutama ketika guru menggunakan strategi umpan balik yang tepat. Namun demikian, di sebagian besar negara-negara Asia, AfL dipraktekkan secara kurang tepat; guru cenderung hanya menerjemahkan kurikulum secara apa adanya; bahkan, mereka lebih cenderung mengetes daripada mengajar, yang seharusnya bersifat membimbing. Untuk merespons masalah kritis tersebut, pada artikel ini, kami ingin mengeksplorasi penilaian untuk pembelajaran (AfL) dalam pembelajaran. Fokus utama artikel ini adalah konsep AfL, tujuan Afl, prasyarat untuk menerapkan AfL, dan pelaksanaan AfL di ruang kelas. Karena praktik AfL sangat penting bagi pembuat kebijakan kurikulum, pemimpin sekolah, dan pendidik guru, kami menawarkan beberapa rekomendasi praktis pada bagian kesimpulan.

Kata Kunci: $\quad$ assessment for learning, pembelajaran siswa, prestasi akademik, dan strategi pemberian umpan balik

\begin{tabular}{llll}
\hline Submitted: Februari 2020 & Reviewed: Maret 2020 & Accepted: Maret 2020 & Published: Maret 2020
\end{tabular}




\section{PENDAHULUAN}

A ssessment for learning (AfL) merupakan salah satu jenis asesmen dalam pembelajaran, terutama pembelajaran pada jalur pendidikan formal dari jenjang pendidikan dasar, pendidikan menengah, hingga pendidikan tinggi. Jenis asesmen yang lain adalah assessment of learning (AoL) dan assessment as learning (AaL). Ada juga jenis asesmen yang disebut formative assessment dan summative assessment. Meskipun tidak sama persis, AfL seringkali disamakan dengan formative assessment. Dalam hal ini Stiggens (dalam Bartlett, 2015) menyatakan bahwa "If formative assessment is about more frequent, assessment for learning isabout continuos. If formative assessmentis about providing teachers with evidence, assessment for learning is about informing the students themselves."

Sebagai bagian yang tak terpisahkan dari sistem pembelajaran, seperti halnya jenis-jenis asesmen yang lain, AfL banyak dikaji dan teliti oleh para pakar dan peneliti. Sejumlah penulis secara khusus menulis buku tentang AfL, seperti Bartlett (2015), Berry (2008), Laveault \& Allal (2016) dan Spendlove (2011). Sejumlah peneliti juga secara khusus mengkaji AfL, yang mencakup berbagai issue seperti penerapan AfL dalam pembelajaran menulis (Lee dan Coniam, 2013), prasyarat penerapan AfL dalam pembelajaran (Heitink, Kleij, Vedkamp, Schildkamp, dan Kippers, 2016), pandangan guru terhadap AfL dan pengambilan keputusan berbasis data (Kippers, Wolterinck, Schildkamp, Poortman, dan Visscer, 2018), dan meta-analisis penelitian Afl di Negara-negara Asia Timur (Leong, Ismail, Costa, dan Tan, 2018).

Apabila dilaksanakan dengan baik, AfL berdampak positif terhadap kualitas pembelajaran (William, 2011). Namun demikian masih banyak guru yang belum memahami konsep AfL (Spenddlove, 2011). Oleh karena itu, tidak mengherankan apabila hanya sedikit guru yang telah melaksankana AfL dalam pembelajaran mereka. Kippers, Wolterinck, Schildkamp, Poortman, dan Visscer, (2018) melaporkan bahwa hanya sekitar 10 hingga 25 persen guru mengintegrasikan AfL dalam pembelajaran mereka di dalam kelas. Di samping keterbatasan pemahaman tentang AfL, para guru juga menghadapi kendala dalam melaksanakan AfL, seperti tekanan orang tua siswa yang masih berorientasi pada nilai ujian nasional (Leong, Ismail, Costa, dan Tan, 2018).

Berdasarkan pada laporan hasil penelitian bahwa belum banyak guru yang memahami dan melaksanakan AfL, melalui artikel ini kami ingin memaparkan konsep AfL dalam pembelajaran di sekolah. Secara lebih khusus dalam artikel ini kami akan menjelaskan konsep AfL, tujuan AfL, prasyarat pelaksanaan AfL, dan pelaksnaan AfL.

\section{METODE PENELITIAN}

Artikel ini ditulis dengan menggunakan metode kepustakaan (Ridley, 2012; Onwuedbuzie \& Frels, 2016; dan Diickson, Cherry, dan Boland, 2017). Mekanisme atau langkah-langkah yang kami tempuh adalah sebagai berikut. Pertama, mencari dan memilih referensi-referensi yang relevan dengan topik yang dibahas (yaitu assessment for learning). Kedua, membaca dan memahami referensi-referensi terpilih tersebut. Ketiga, melakukan analisis kritis terhadap referensi-referensi terpilih itu, dengan mengidentifikasi kelebihan dan kelemahan masing-masing referensi terpilih. Keempat, melakukan analisis komparatif terhadap referensi-referensi terpilih berdasarkan pada hasil analisis kritis. Kelima, mengambil keputusan, yaitu referensi mana yang dipilih dan digunakan sebagai bahan untuk penulisan artikel ini. Referensi yang kami gunakan merupakan kombinasi antara referensi yang berupa buku dan artikel hasil penelitian dari jurnal ilmiah yang kredibel. 


\section{HASIL DAN PEMBAHASAN}

Sesuai dengan tujuannya, sebagaimana telah kami sampikan di Bagian Pendahuluan, artikel ini akan menjelaskan dan membahas empat hal terkait dengan AfL, yaitu konsep AfL, tujuan AfL, prasyarat pelaksanaan AfL, dan pelaksnaan AfL. Masing-masing dikemukakan di bawah ini.

\section{Konsep AfL}

Ada sejumlah pengertian tentang AfL yang dikemukakan oleh para ahli. Salah satu di antaranya adalah pengertian AfL yang dikemukakan oleh Klenowski (2009). Dinyatakan bahwa "Assessment for Learning is part of everyday practice by students, teachers and peers that seeks, reflects upon and responds to information from dialogue, demonstration and observation in ways that enhance ongoing learning." Ada empat frasa kunci dalam pengertian tersebut, yaitu everyday practice; by students, teachers and peers; seeks, reflects upon and responds to; dan in ways that enhance ongoing learning.

"Everyday practice" dalam pengertian di atas merujuk pada kegiatan belajar-mengajar yang di menekankan adanya hubungan interaktif, dialogis, dan timbal balik antara guru dan siswa. Hal itu berarti bahwa AfL terjadi dan menjadi satu kesatuan dalam kegiatan belajar-mengajar. 'By students, teachers and peers' mengandung pengertian bahwa AfL pada dasarnya berpusat pada siswa (student centred). Semua praktek AfL yang dilakukan oleh guru (seperti memberi feedback, menentukan kriteria keberhasilan belajar, dan memberikan pertanyaan) pada akhirnya dapat diberikan kepada siswa sehingga mereka mengambil alih praktek-praktek AfL tersebut untuk membantu mereka sendiri agar mereka menjadi pembelajar yang mandiri (autonomous learners). "Seeks, reflects upon and responds to" menekankan sifat AfL sebagai proses inkuiri yang melibatkan pencarian dan pengumpulan bukti (evidence) tentang kemampuan dan pemahaman siswa, memaknai bukti tersebut, dan mengambil keputusan tentang apa yang perlu dilakukan oleh guru dan siswa selanjutnya. 'In ways that enhance ongoing learning' berarti bahwa AfL bertujuan untuk meningkatkan kualitas proses pembelajaran.

Dalam kaitannya dengan butir tearkhir, bahwa AfL meningkatkan kualitas proses pembelajaran, sebuah kelompok yang bernama Assessment Reform Group (Berdiri tahun 1989 di Inggris), yaitu kelompok yang didedikasikan untuk meyakinkan bahwa kebijakan dan praktek asesmen harus didasarkan pada hasil penelitian (research evidence), mengusulkan tujuh kriteria agar asesmen dapat mengembangkan pembelajaran. Ketujuh kriteria tersebut adalah sebagai berikut. Pertama, asesmen harus menyatu dengan kegiatan pembelajaran dan menjadi bagian penting dari pembelajaran tersebut. Kedua, guru harus menjelaskan tujuan pembelajaran kepada siswa. Ketiga, guru menegosiasikan standar keberhasilan pembelajaran dengan siswa. Keempat, guru melibatkan siswa untuk melakukan penilaian diri (self-assessment). Kelima, asesmen memberikan feedback yang menjadikan siswa memahami apa yang perlu mereka lakukan dan bagaimana mereka melakukannya. Keenam, asesmen dilandasi oleh kepercayaan atau keyakinan (confidence) bahwa setiap siswa dapat berkembang. Ketujuh, baik guru maupun siswa mereview dan merefleksi data hasil asesmen (William, 2011).

Ketika mencoba membandingkan antara AoL, AfL, dan AaL, Sadeghi dan Rahmati (2017) menyampaikan lima komponen pembeda, yaitu waktu, tujuan, alat, komponen utama, dan asesor. Dilihat dari aspek waktu, AfL bersifat iterative dan terjadi sepanjang berlangsungnya kegiatan pembelajaran. Tujuan AfL adalah untuk memperoleh pendapat yang bersifat formative dan untuk mengidentifikasi kelebihan dan kelemahan siswa. Alat yang digunakan untuk mencapai tujuan tersebut meliputi portofolio, jurnal, wawancara, pengamatan, konferensi, dan projek. Komponen utama dalam AfL adalah feedback, baik untuk siswa maupun untuk guru. Asesor dalam AfL adalah guru.

\section{Tujuan AfL}


Tujuan utama dari AfL adalah mengembangkan atau meningkatkan kualitas proses pembelajaran (enhancing ongoing learning). Siswa tidak hanya memperoleh pengetahuan dan pengalaman dari proses pembelajaran tersebut, tetapi juga mengembangkan kemampuan metakognisi, yang mengarahkan mereka untuk menjadi pembelajar yang mandiri, di mana mereka bertanggung jawab atas pembelajarannya sendiri (Black and William, 1998; Miedijensky and Tal, 2016; and Kippers, Wolterinck, Chritel, Kim; Poortman, and Visscher, 2018). Dengan kata lain, suatu proses pembelajaran dianggap berkualitas apabila proses pembelajaran tersebut mampu menjamin pemerolehan pengetahuan dan pengamalaman oleh siswa (tahap kognisi), mampu mengembangkan kemampuan metakognisi siswa (tahap metakognisi), dan mampu menjadikan siswa pembelajar yang mandiri (tahap otonomi).

Indikator pertama proses pembelajaran yang berkualitas adalah diperolehnya atau bertambahnya pengetahuan dan keterampilan oleh siswa (tahap kognisi). Berbagai metode pembelajaran bahasa seperti the grammar-translation method, the direct method, theaudio-lingual method, the silent way, community language learning, communicative language teaching, content-based instruction, taskbased language teaching, text-based instruction, dan natural approach (Freeman \& Anderson, 2010 dan Richards \& Rodgers, 2014) -- digunakan oleh guru dalam kegiatan pembelajaran bahasa agar siswa dapat memahami apa yang mereka pelajari.

Untuk mengetahui apakah siswa benar-benar memperoleh pengetahuan dan pengalaman melalui kegiatan pembelajaran, guru perlu melakukan pengecekan. Hal ini penting untuk dilakukan oleh guru karena siswa memiliki tingkat kemampuan dan kecepatan belajar yang berbeda-beda. Ada siswa yang masuk dalam kelompok pembelajar cepat (fast learners) tetapi ada juga siswa yang masuk kelompok pembelajar lambar (slow learners). Sementara itu, guru sebagai fasilitator dan pembimbing harus menjamin bahwa semua siswa harus mampu mencapai tujuan pembelajaran yang telah ditentukan. Untuk mengecek pemahaman tersebut, guru dapat menggunakan beberapa teknik untuk mengecek pemahaman siswa seperti oral language, questions, writing, projects and performances, tests, dan common assessments (Fisher dan Frey, 2007).

Indikator kedua proses pembelajaran yang berkualitas adalah berkembangnya kemampuan metakognisi siswa (tahap metakognisi). Kalau pada tahap kognisi penekanan terletak pada apakah melalui kegiatan pembelajaran siswa mampu memperoleh atau menambah pengetahuan dan pengalamannya, pada tahap metakognisi penekanan terletak pada bagaiamana siswa mengetahui proses pemerolehan pengetahuan dan pengalaman tersebut. Miedijensky dan Tal (2016) mendefinisikan metakognisi sebagai "knowledge and awareness of the individual's own cognitive processes and the ability to monitor, regulate and evaluate one's thinking." Pengembangan kemampuan metakognisi memerlukan peran aktif siswa dalam mengkonstruksi pengetahuan dan pengalamannya dan kemampuan siswa dalam memonitor dan mengontrol kemajuan belajarnya.

Dalam kaitannya dengan upaya pengembangan kemampuan metakognisi siswa, berbagai metode yang lebih berorientasi kepada siswa (student-centered methods) direkomendasikan untuk digunakan. Metode yang dimaksud adalah student-centred approaches, inquiry-based methods, discovery learning, problem-based learning, project-based learning, resourse-based learning, dan computerassisted learning (Westwood, 2008). Dalam Kurikulum 2013, Pemerintah Indonesia merekomendasikan penggunaan pendekatan ilmiah (scientific approach), yang meliputi lima langkah: mengamati, menanya, mengumpulkan informasi, menalar/mengasosiasi, dan mengomunikasikan. Penggunaan metode ilmiah tersebut untuk menjamin bahwa siswa tidak hanya menerima pengetahuan dan pengalaman dari guru, tetapi siswa mampu mengkonstruksi pengetahuan dan pengalamannya sendiri.

Indikator ketiga proses pembelajaran yang berkualitas adalah bahwa pengembangan kemampuan metakognisi mampu mengantarkan siswa menjadi pembelajar yang mandiri (autonomous learners). Secara umum, otonomi dapat didefinisikan sebagai "the capacity to take control over one's own 
learning." (Benson, 2001). Kata kunci untuk menjadi pembelajar mandiri adalah kemampuan mengelola pembelajarannya sendiri. Konsep ini mengoreksi beberapa miskonsepsi yang terjadi di masyarakat yang menyatakan bahwa belajar mandiri adalah belajar sendiri, belajar tanpa guru, dan belajar di laur kelas (Benson, 2001). Hasil penelitian yang dilakukan oleh Cotteral dan Crabbe (1992) terhadap pembelajar bahasa menunjukkan bahwa pembelajar yang mandiri adalah pembelajar yang (1) merencanakan dan mengorganisasi sendiri pengalaman belajarnya, (2) mengetahui bidang-bidang yang menjadi fokus pemelajaran, (3) memantau sendiri kemajuan belajarnya, (4) mencari kesempatan untuk berlatih, (5) memiliki antusiasme terhadap bahasa dan belajar bahasa, dan (6) memiliki kepercayaan diri untuk menggunakan bahasa dan mencari bantuan apabila diperlukan.

Benson (2001) mengusulkan enam pendekatan pengembangan pembelajaran mandiri (autonomous learning), yaitu resource-based approaches (menekankan hubungan independen dengan materi ajar), technology-based approach (menekankan hubungan independen dengan teknologi pendidikan), learner-based approach (menekankan terjadinya perubahan perilaku dan psikologis siswa), classroom-based approach (menekankan kemampuan siswa dalam mengontrol perencanaan dan evaluasi pembelajarannya, terutama pembelajaran di dalam kelas), curriculum-based approaches (memperluas konsep kemampuan siswa mengontrol pembelajaran ke kurikulum secara keseluruhan), dan teacher-based approaches (menekankan peran guru dan calon guru dalam mengembangkan pembelajaran mandiri di kalangan siswa).

\section{Prasyarat Pelaksanaan AfL}

Agar AfL dapat terlaksana dengan baik, sejumlah prasyarat perlu dipenuhi. Paling tidak ada empat kategori prasyarat yang dimaksud, yaitu kategori asesmen, kategori guru, kategori siswa, dan kategori konteks (Lee and Coniam, 2013; Kippers, Wolterinck, Schildkamp, Poortman, Visscher, 2018).

Kategori asesmen meliputi empat parameter. Pertama, asesmen harus menjadi satu kesatuan dan terintegrasi dalam kurikulum. Dalam pengertian yang sempit, kurikulum direalisasikan dalam bentuk rencapa pelaksanaan pembelajaran (RPP) atau rencana pembelajaran semester (RPS). Jenis dan teknik asessmen harus dicantumkan dan dijelaskan dalam dokumen kurikulum (RPP atau RPS) tersebut. Kedua, asesmen harus menghasilkan dan memberikan feedback yang rinci tentang pembelajaran siswa. Feedback dapat dibagi menjadi dua, yaitu cognitive feedback dan affective feedback. Affective feedback dapat dibedakan menjadi positive affective feedback dan negative affective feedback. Dalam pelaksanaan pembelajaran, kedua jenis feedback (cognitive dan affective) dapat dikombinasikan. Ketiga, asesmen harus terintegrasi dengan pembelajaran di dalam kelas. Fungsi AfL dalam pembelajaran meliputi monitoring kemajuan pembelajaran siswa, pemberian feedback kepada siswa, dan mengoreksi kesalahan yang dibuat oleh siswa. Ketiga fungsi tersebut terjadi selama kegiatan pembelajaran berlangsung, mulai dari menit pertama hingga menit terakhir. Keempat, asesmen harus dilaksanakan dengan baik. AfL yang baik adalah AfL yang berfungsi sebagaimana mestinya (parameter ketiga), dan hal ini sangat tergantung pada pelaksana AfL, yaitu guru. Implikasinya adalah bahwa guru harus memahami konsep dan pelaksnaan AfL dengan baik.

Kategori guru terdiri atas empat parameter. Pertama, guru harus memiliki pengetahuan dan keterampilan untuk mengumpulkan, menganalisis, dan menginterpretasikan bukti (evidence) kemajuan belajar siswa, serta mengambil langkah yang tepat untuk menindaklanjuti hasil interpretasi tersebut. Kedua, Guru harus memiliki pengetahuan dan keterampilan untuk mengadaptasi cara mengajarnya sesuai dengan konteks berlangsungnya pembelajaran, karena pembelajaran tidak terjadi dalam ruang yang vakum, melainkan dalam situasi tertentu yang sangat kompleks, dinamis, dan tidak dapat diprediksi. Ketiga, guru harus memiliki pengetahuan dan keterampilan dalam mengintegrasikan teknologi dalam pembelajaran. Mengintegrasikan teknologi tidak hanya mencakup merencanakan, melaksanakan, dan mengevaluasi penggunaan teknologi dalam pembelajaran, melainkan juga mencakup etika dan keselamatan menggunakan teknologi. Keempat, guru harus memiliki sikap 
(attitude) yang positif terhadap penggunaan atau pelaksanaan AfL. Sikap positif tersebut ditunjukkan dengan kemauan untuk memahami konsep AfL dan melaksanakannya dengan baik pula.

Kategori siswa memiliki tiga parameter. Pertama, siswa harus terlibat secara aktif dalam proses pembelajaran. Keterlibatan aktif siswa dalam kegiatan belajar-mengajar dapat dicapai apabila mereka memiliki kesempatan untuk secara langsung melakukan berbagai bentuk pengkajian untuk memperoleh pengetahuan dan pemahaman; berlatih berbagai keterampilan kognitif, personal-sosial, dan psikomotorik; dan menghayati berbagai peristiwa sarat nilai baik secara pasif dalam bentuk pengamatan dan pengkajian maupun secara aktif melalui keterlibatan langsung di dalam berbagai kegiatan serta peristiwa sarat nilai (Joni, 1993). Kedua, siswa harus memahami tujuan pelajaran. Pada tahap pendahuluan, guru perlu menyampaikan tujuan pelajaran, yang berisi cakupan materi yang akan dipelajarai siswa, sehingga siswa memahami apa yang akan dipelajari. Ketiga, siswa perlu dilibatkan dalam proses penialian diri dan penilaian sebaya untuk mengembangkan kesadaran diri tentang apa yang masih lemah dan bagaimana memperbaikinya. Paling tidak ada tiga tahap penilaian diri dan sebaya, yaitu penilaiaan terbimbing (guided assessment), penilaian dengan bantuan aplikasi teknologi (assisted assessment), dan penilaian bebas. Untuk dapat menjalankan penilaian dengan baik, siswa perlu menjalani pelatihan (training) yang cukup.

Kategori konteks terdiri atas lima parameter. Pertama, pimpinan sekolah harus menyediakan fasilitas dan memberi dukungan terhadap pelaksnaan AfL. Fasilitas dan dukungan yang dimaksud dalam hal ini setidaknya mencakup fasilitas dan dukungan yang diusulkan oleh Benson (2001) agar tercipta autonomous learning. Kedua, pimpinan sekolah harus memberi motivasi baik kepada guru maupun siswa untuk menciptakan proses pembelajaran yang berkualitas. Salah satu bentuk motivasi adalah memenuhi fasilitas pembelajaran dan memberi insentif kepada guru dan siswa yang berprestasi. Ketiga, pimpinan sekolah juga harus memiliki pengatahuan dan keterampilan untuk menganalisis dan menginterpretasikan informasi akademik yang diberikan oleh siswa. Selanjutnya, pempinan sekolah harus mampu mengambil langkah yang tepat sebagai tindak lanjut. Keempat, guru perlu melakukan kolaborasi antar guru, paling tidak guru-guru yang mengajar mata pelajaran yang sama (MGMP sekolah). Mereka perlu secara periodik melakukan sharing pengalaman tentang best practices yang pernah dilakukan, sehingga mereka saling belajar. Kelima, sebagai bagian dari fasilitas pembelajaran, sekolah perlu melengkapi diri dengan teknologi yang memungkinkan pembelajaran versi 4.0 dapat berlangsung dengan baik.

\section{Pengalaman Pelaksanaan AfL di Negara-Negara Asia}

Leong, Ismail, Costa, dan Tan (2018) melakukan meta-analisis terhadap 24 artikel hasil penelitian tentang Afl di Negara-negara Asia Timur, yang meliputi Indonesia, Hongkong, China, Brunai, Singapura, Philipina, Taiwan, Malaysia, dan Korea Selatan. Hasilnya adalah sebagai berikut. Pertama, hampir semua artikel menempatkan feedback pada posisi sentral dalam AfL, baik feedback untuk guru (yang berfungsi untuk memodifikasi cara mengajarnya) maupun untuk siswa (yang berfungsi untuk meningkatkan kualitas pembelajaran mereka. Kedua, terkait dengan penggunaan istilah, dari 24 artikel, 11 buah artikel menggunakan istilah "formative assessment", 8 buah artikel menggunakan istilah "formative assessment" dan "assessment for learning" secara bergantian, dan hanya 1 buah artikel yang membedakan antara "formative assessment" dan "assessment for Learning". Di sebagian besar artikel, para peneliti memaknai "formative assessmenf' dan/atau "assessment for learning" sebagai penilaian yang bertujuan untuk memperbaiki pembelajaran siswa pada saat berlangsungnya kegiatan pembelajaran.

Dalam kaitannya dengan pelaksanaan AfL di lapangan, dinyatakan bahwa hambatan terbesar pelaksnaan AfL adalah tekanan yang datang dari ujian nasional. Guru yang percaya dengan AfL tidak dapat melaksanakan AfL karena mereka harus menyiapkan ujian bagi mereka. Perhatian siswa yang terfokus pada ujian nasional juga dianggap menjadi hambatan pelaksanaan AfL. Siswa tidak mampu 
melihat kaitan antara apa yang mereka pelajari dan bagaimana apa yang mereka pelajari itu membantu mereka dalam ujian. Hambatan lain adalah dominasi guru di dalam kelas. Guru selalu memberikan jawaban yang benar kepada siswa, dengan meninggalkan ruang yang sangat kecil bagi proses dialogis yang memungkinkan siswa mengkonstruksi pengetahuan dan pengalamannya sendiri. Beberapa guru meyakini kelebihan AfL, tetapi terhambat oleh nilai-nilai kelembagaan dan budaya sekolah, yang menyatakan bahwa pemerolehan nilai dan peringkat masih menjadi bagian penting dari pembelajaran. Terakhir, guru memiliki pengetahuan dan keterampilan yang terbatas tentang AfL.

\section{KESIMPULAN DAN REKOMENDASI}

Dari uraian pada Bagian Hasil dan Pembahasan dapat disimpulkan bahwa Assessment for Learning adalah bagian dari kegiatan pembelajaran sehari-hari yang dilakukan oleh guru dan siswa untuk mencari, merefleksi, dan merespons setiap informasi akademik yang berasal dari dialog, demonstrasi, observasi, dan bentuk-bentuk lain yang relevan (yang terjadi di dalam kelas) yang dapat meningkatkan kualitas pembelajaran. Tujuan utama dari AfL adalah meningkatkan kualitas proses pembelajaran. Siswa tidak hanya memperoleh pengetahuan dan pengalaman dari proses pembelajarannya, tetapi juga mengembangkan kemampuan metakognisi, yang mengarahkan mereka untuk menjadi pembelajar yang mandiri. Agar AfL dapat terlaksana dengan baik, sejumlah prasyarat perlu dipenuhi, yang secara garis besar meliputi empat kategori, yaitu kategori asesmen, kategori guru, kategori siswa, dan kategori konteks. Meskipun AfL sangat penting dalam meningkatkan kualitas pembelajran, dalam pelaksanaannya belum semua guru menerapkannya di dalam kelas. Pelaksanaan Afl terkendala oleh adanya ujian nasional yang menjadi stressor baik oleh guru maupun siswa, sifat dominasi guru terhadap siswa, dan pengetahuan guru yang terbatas terhadap AfL.

Bertitik tolak dari kesimpulan di atas, kami memberikan saran sebagai berikut. Pertama, pengembang kurikulum di tingkat pusat perlu membuat panduan yang rinci tentang assessment for learning agar bisa diimplementasikan oleh guru. Panduan penilaian yang beredar selama ini masih bersifat sangat umum. Kedua, kepala sekolah perlu menyampaikan kepada para guru dan sekaligus memberi dukungan atas kebijakan bahwa kualitas pembelajaran sangat penting untuk diwujudkan, sebagai bagian yang tidak terpisahkan dari terwujudnya hasil belajar siswa. Guru perlu dimotivasi dan sekaligus dibimbing (oleh kepala sekolah) untuk mengajar dengan baik, dan bukan hanya menilai. Ketiga, untuk dapat melaksanakan AfL dengan benar dan baik, guru perlu meningkatkan pengetahuan dan keterampilan tentang AfL. Guru perlu meng-update referensi mereka tentang AfL dan membahasnya dengan sesame kolega di forum-forum guru, seperti MGMP.

\section{DAFTAR PUSTAKA}

Bartlett, Jayne. (2015). Outstanding assessment for learning in the classroom. London: Routledge.

Benson, Phil. (2001). Teaching and researching autonomy in language learning. Hartlow: Longman.

Berry, Rita. (2008). Assessment for learning. Hongkong: Hongkong University Press.

Black, Paul dan William, Dylan. (2018). Classroom assessment and pedagogy. Assessment in education: Principles, policy \& practice 1-26.

Cotteral, Sara dan Crabbe, David. (1992). Fostering autonomy in the language classroom: Implications for teacher education. Guidelines, vol. 14 No. 2 Desember. Singapura: SEAMEO Regional Language Centre.

Crooks, Terry. (2011). Assessment for learning in the accountability era: New Zealand. Studies in educational evaluation 37, 71-77. 
Dickson, Rumona; Cherry, M. Gemma; dan Boland, Angela. (2017). Carrying out a systematic review as a master's thesis. Dalam Angela Boland, M.Gemma Cherry, dan Rumona Dickson (eds.), Doing a systematic review: A student's guide (pp. 1-20). Los Angeles: Sage.

Fisher, Douglas dan Frey, Nancy. (2007). Checking for understanding: Formative assessment techniques for your classroom. Alexandria, Virginia: Association for Supervision and Curriculum Development.

Freeman, Diane Larsen dan Anderson, Marti. (2011). Techniques \& principles in language teaching. Oxford: Oxford University Press.

Heitink, M.C.; Kleij, F.M Van der; Veldkamp, B.P.; Schildkamp, K; dan Kippers, W.B. (2016). A systematic review of prerequisites for implementing assessment for learning in classroom practice. Educational research review 17 (2016) 50-62.

Joni, T. Raka. (1993). Pendekatan cara belajar siswa aktif: Acuan konseptual peningkatan mutu kegiatan belajar-mengajar. Dalam Conny R. Semiawan dan T. Raka Joni (eds.), Pendekatan pembelajaran: Acuan konseptual pengelolaan kegiatan belajar-mengajar di sekolah. (Jakarta: Konsorsium IImu Pendidikan, Ditjen Dikti, Depdikbud.

Kippers, Wilma B.; Wolterinck, Christel H.D.; Schildkamp, Kim; Poortman, Cindy L.; dan Visscher, Andrie J. (2018).Teachers' views on the use of assessment for learning and data-based decision making in classroom practice. Teaching and teacher education 75, 199-213.

Klenowski, V. (2009). Editorial: Assessment for learning revisited: An Asia-Pacific perspective. Assessment in Education: Principles, Policy, and Practice, 16(3), 263-268.

Laveault, Dany dan Allal, Linda. (2016). Assessment for learning: Meeting the challenge of implementation. New York: Springer.

Lee, Icy dan Coniam, David. (2013). Introducing assessment for learning for EFL writing in an assessment of learning examination-driven system in Hong Kong. Journal of second language writing 22 (2013) 34-50.

Leong, Wei Shin; Ismail, Haslinda; Costa, Jolene Sonia; dan Tan, Hong Boon. (2018). Assessment for learning research in East Asian countries. Studies in educational evaluation 59 (2018) 270-277.

Miedijenskya, Shirley dan Tal, Tali. (2016). Reflection and assessment for learning in science enrichment courses for the gifted. Studies in educational evaluation 50, 1-13.

Onwuegbuzie, Anthony J. dan Frels, Rebecca. (2016). 7 steps to a comprehensive literature review: A multimodal \& cultural approach. Los Angeles: Sage.

Richards, Jack C dan Rodgers, Theodore S. (2014). Approaches and metods in language teaching. Cambridge: Cambridge University Press.

Ridley, Dianna. (2012). The literature review: A step-by-step guide for students (2 ${ }^{\text {nd }}$ Edition). Los Angeles: Sage.

Sadeghi, Karim dan Rahmati, Teymour. (2017). Integrating assessment as, for, and of learning in a large-scale exam preparation course. Assessing writing $34,50-61$.

Splendlove, David. (2011). Putting assessment for learning in practice. London: Continum.

Westwood, Peter. (2008). What teachers need to know about teaching methods. Victoria: Acer Press.

William, Dylan. (2011). What is assessment for learning? Studies in educational evaluation 37, 3-14.

How to cite: Nurkamto, J \& Sarosa, T. (2020). Assesment for learning dalam pembelajaran bahasa di sekolah. Teknodika, 18 (1), 63-70. DOI: https://doi.org/10.20961/teknodika.v18i1.40408 